\title{
Contribution of Family Relatedness to Neurobehavioral Comorbidities in Idiopathic Childhood Epilepsies
}

\author{
Dace N. Almane, ${ }^{1}$ Qianqian Zhao, ${ }^{2}$ Paul J. Rathouz, ${ }^{2}$ Melissa Hanson, ${ }^{1}$ Daren C. Jackson, ${ }^{1}$ David A. Hsu, ${ }^{1}$ \\ Carl E. Stafstrom, ${ }^{3}$ Jana E. Jones, ${ }^{1}$ Michael Seidenberg, ${ }^{4}$ Monica Koehn, ${ }^{5}$ And Bruce P. Hermann ${ }^{1}$ \\ ${ }^{1}$ Department of Neurology, University of Wisconsin School of Medicine and Public Health, Madison, Wisconsin \\ ${ }^{2}$ Department of Biostatistics and Medical Informatics, University of Wisconsin School of Medicine and Public Health, Madison, Wisconsin \\ ${ }^{3}$ Department of Neurology, Johns Hopkins University School of Medicine, Baltimore, Maryland \\ ${ }^{4}$ Department of Psychology, Rosalind Franklin University of Medicine and Science, North Chicago, Illinois \\ ${ }^{5}$ Marshfield Clinic Neurosciences, Marshfield Clinic, Marshfield, Wisconsin
}

(Received November 7, 2017; Final Revision February 9, 2018; Accepted February 23, 2018; First Published Online May 10, 2018)

\begin{abstract}
Objectives: Rates of cognitive, academic and behavioral comorbidities are elevated in children with epilepsy. The contribution of environmental and genetic influences to comorbidity risk is not fully understood. This study investigated children with epilepsy, their unaffected siblings, and controls to determine the presence and extent of risk associated with family relatedness across a range of epilepsy comorbidities. Methods: Participants were 346 children (8-18 years), $n=180$ with recent-onset epilepsy, their unaffected siblings $(n=67)$, and healthy first-degree cousin controls $(n=99)$. Assessments included: (1) Child Behavior Checklist/6-18 (CBCL), (2) Behavior Rating Inventory of Executive Function (BRIEF), (3) history of education and academic services, and (4) lifetime attention deficit hyperactivity disorder (ADHD) diagnosis. Analyses consisted of linear mixed effect models for continuous variables, and logistic mixed models for binary variables. Results: Differences were detected between the three groups of children across all measures $(p<.001)$. For ADHD, academic problems, and executive dysfunction, children with epilepsy exhibited significantly more problems than unaffected siblings and controls; siblings and controls did not differ statistically significantly from each other. For social competence, children with epilepsy and their unaffected siblings displayed more abnormality compared with controls, with no statistically significant difference between children with epilepsy and unaffected siblings. For behavioral problems, children with epilepsy had more abnormality than siblings and controls, but unaffected siblings also exhibited more abnormalities than controls. Conclusions: The contribution of epilepsy and family relatedness varies across specific neurobehavioral comorbidities. Family relatedness was not significantly associated with rates of ADHD, academic problems and executive dysfunction, but was associated with competence and behavioral problems. (JINS, 2018, 24, 653-661)
\end{abstract}

Keywords: Epilepsy, Children, ADHD, Behavior, Executive function, Genetics

\section{INTRODUCTION}

An extensive literature that includes population-based, community-based and clinical investigations has documented significantly elevated rates of a variety of neurobehavioral comorbidities in children with epilepsy, including behavioral problems (i.e., depression, anxiety, attention deficit hyperactivity disorder [ADHD]), lower social competence, academic difficulties, and executive dysfunction (Almane et al., 2015; Berg et al., 2007; Hoie et al., 2005; Jones et al., 2008; Lin, Mula, \& Hermann, 2012; MacAllister

Correspondence and reprint requests to: Dace Almane, Department of Neurology, University of Wisconsin School of Medicine and Public Health, MFCB, Room 7220, 1685 Highland Avenue, Madison, WI 53705. E-mail: almane@neurology.wisc.edu
\& Schaffer, 2007; Parrish et al., 2007; Rantanen, Eriksson, \& Nieminen, 2012; Russ, Larson, \& Halfon, 2012). These elevated rates of neurobehavioral comorbidities have been demonstrated in comparison with typically developing children as well as in comparison to children with other medical disorders such as asthma, diabetes, cardiac problems, and other physical problems (Austin et al., 2001; Austin, Huberty, Huster, \& Dunn, 1998; Davies, Heyman, \& Goodman, 2003; Hoare, 1984; McDermott, Mani, \& Krishnawami, 1995; Rutter, Graham, \& Yule, 1970).

The timing and course of the neurobehavioral comorbidities in childhood epilepsy have become increasingly clear, and it is now appreciated that many behavioral and cognitive problems can be observed in children with new onset epilepsy, suggesting that these complications are not the consequence of a course of prolonged poorly controlled 
epilepsy and its treatment or psychosocial complications (Austin et al., 2001; Fastenau et al., 2009; Oostrom et al., 2003). Furthermore, behavioral problems (Austin et al., 2001), academic struggles (Berg et al., 2005; McNelis, Johnson, Huberty, \& Austin, 2005; Overvliet, Aldenkamp, Klinkenberg, Vles, \& Hendriksen, 2011), and rates of specific psychiatric comorbidities (i.e., depression, anxiety, ADHD) (Hesdorffer et al., 2004; Jones et al., 2007) have been reported even antecedent to the first recognized seizure and epilepsy diagnosis, implicating antecedent neurodevelopmental dysmaturation (Pohlmann-Eden et al., 2015).

An issue of increasing interest is the degree to which there may be aggregation of neurobehavioral contributions in unaffected siblings and even parents of children with epilepsy (Chowdhury et al., 2014; Clarke et al., 2007; Hesdorffer, Caplan, \& Berg, 2012; Iqbal et al., 2015; Levav et al., 2002; Smith et al., 2012). It is possible that genetics and/or family environment may contribute to the observed increased risk of cognitive and behavioral problems in children with epilepsy. While comparisons of probands with epilepsy to unaffected siblings have been shown to exhibit increased rates of neurobehavioral comorbidities in children with epilepsy, including children with new onset epilepsy (e.g., Austin et al., 2001; Berg et al., 2007), other studies have included unrelated controls from which unaffected siblings have been found to differ as well as the children with epilepsy (Aronu \& Iloeje, 2011; Chowdhury et al., 2014; Iqbal et al., 2015). In the epilepsy literature, studies that demonstrate neuroimaging differences in unaffected siblings that mirror or approach those seen in the probands with epilepsy (Alhusaini et al., 2013; Badawy, Vogrin, Lai, \& Cook, 2013; Wandschneider et al., 2014), also raise the question of a contribution of familial relatedness.

Compared to prior investigations (McNelis et al., 2005; Sherman, Slick, Connolly, \& Eyrl, 2007), we investigate a broader range of potential neurobehavioral comorbidities (Hesdorffer et al., 2004; McNelis et al., 2005; Sherman et al., 2007). In the current study, we examined parent-reported behavior problems and social competence, rates of DSM-IV ADHD, academic problems, and markers of executive dysfunction, all of which have been reported to be elevated in children with epilepsy, including new-onset epilepsy. By comparing children with epilepsy with unaffected siblings and typically developing controls, we sought to understand which comorbidities appear to be influenced by family relatedness and which are independent of family relatedness. Consistent with prior research, we hypothesize that the siblings of children with epilepsy will have lower rates of comorbidities and behavior problems compared to children with epilepsy, but higher rates than the healthy controls.

\section{METHODS}

\section{Participants}

Research participants consisted of 346 children aged 8-18 years, including youth with recent-onset epilepsy (probands, $n=180)$, their unaffected siblings $(n=67)$, and healthy first-degree cousin controls $(n=99)$. All participants attended regular schools at the time of the study assessment visit. Children with epilepsy were recruited from pediatric neurology clinics at three Midwestern medical centers (University of Wisconsin-Madison, Marshfield Clinic, Dean Clinic) and met the following inclusion criteria: (i) diagnosis of epilepsy within the past 12 months; (ii) no other developmental disabilities (e.g., intellectual impairment, autism); (iii) no other neurological disorder, and (iv) a brain MRI scan obtained as part of routine clinical care that was interpreted as normal. All children entered the study with active epilepsy diagnosed by their treating pediatric neurologists and confirmed by medical record review by the research study pediatric neurologist. We did not exclude children on the basis of psychiatric comorbidities (including ADHD) or learning disabilities. In general, we tried to stay true to the concept of "epilepsy only" as defined broadly in the literature by normal neurological examinations, intelligence, and attendance at regular schools.

Each child's epilepsy syndrome was defined in a research consensus meeting by the research pediatric neurologists who reviewed all available clinical data (e.g., seizure description and phenomenology, electroencephlogram, clinical imaging, neurodevelopmental history) while blinded to all research cognitive, behavioral, and neuroimaging data. Two levels of epilepsy syndrome classification were undertaken and confirmed by two board-certified pediatric neurologists who were blinded to all research data. Children with epilepsy were first classified into broad syndrome groups including generalized epilepsies (GE) and focal epilepsies (FE), followed by classification into specific GE syndromes [juvenile myoclonic epilepsy (JME), childhood and juvenile absence (Absence), and GE not otherwise specified (NOS)] and FE [benign epilepsy with centrotemporal spikes (BECTS), temporal lobe epilepsy (TLE), frontal lobe epilepsy (FLE), benign occipital epilepsy (BOE), and FE not otherwise specified (NOS)].

First-degree cousins were used as controls, and exclusion criteria were as follows: (i) history of any initial precipitating insult (e.g., simple or complex febrile seizures, cerebral infections, perinatal stroke); (ii) any seizure or seizure-like episode; (iii) diagnosed neurological disease; (iv) loss of consciousness greater than $5 \mathrm{~min}$; (v) other family history of a first-degree relative with epilepsy or febrile convulsions. Unaffected siblings comprised all available siblings of the participants with epilepsy ranging in age 8-18 years meeting criteria (i), (ii), and (iii) specified for the healthy controls. Demographic characteristics of the participants are provided in Table 1.

We have demonstrated that use of first degree cousins as controls does not confer bias. It is possible that, compared to population controls, first degree cousins may share genetic predisposition to cognitive and behavioral problems. If this were the case, one would anticipate that there would be a degree of association between children with epilepsy and controls across measures of cognition, behavior, and even brain structure. In a recent investigation (Hanson et al., 2017) we compared 37 children with new onset epilepsy and all their enrolled cousin controls across 42 measures of 
Table 1. Sample demographics

\begin{tabular}{|c|c|c|c|c|}
\hline & $\begin{array}{l}\text { Controls } \\
(N=99)\end{array}$ & $\begin{array}{l}\text { Siblings } \\
(N=67)\end{array}$ & $\begin{array}{c}\text { Epilepsy } \\
(N=180)\end{array}$ & $p$-Value \\
\hline Gender: & & & & .898 \\
\hline Male & $51(51.5 \%)$ & $32(48.5 \%)$ & $88(48.9 \%)$ & \\
\hline Female & $48(48.5 \%)$ & $34(51.5 \%)$ & $92(51.1 \%)$ & \\
\hline Age in years: $M(S D)$ & $12.08(2.96)$ & $13.11(2.73)$ & $11.70(3.09)$ & .005 \\
\hline Ethnicity: Hispanic / non-Hisp / unk & $0 / 99 / 0$ & $3 / 63 / 1$ & $10 / 169 / 1$ & .127 \\
\hline Race: & & & & .225 \\
\hline American Indian & $0(0.0 \%)$ & $0(0.0 \%)$ & $1(0.6 \%)$ & \\
\hline Asian & $0(0.0 \%)$ & $2(3.0 \%)$ & $2(1.1 \%)$ & \\
\hline Black & $1(1.0 \%)$ & $4(6.0 \%)$ & $11(6.1 \%)$ & \\
\hline White & $92(92.9 \%)$ & $58(86.6 \%)$ & $149(82.8 \%)$ & \\
\hline More than 1 race & $6(6.1 \%)$ & $3(4.5 \%)$ & $13(7.2 \%)$ & \\
\hline Unknown & $0(0 \%)$ & $0(0 \%)$ & $4(2.2 \%)$ & \\
\hline Mother's level of education: & & & & .084 \\
\hline High school or less & $35(35.4 \%)$ & $12(17.9 \%)$ & $59(32.8 \%)$ & \\
\hline Some college & $20(20.2 \%)$ & $21(31.3 \%)$ & $55(30.6 \%)$ & \\
\hline Bachelor's degree & $28(28.3 \%)$ & $23(34.3 \%)$ & $41(22.8 \%)$ & \\
\hline Master's degree or higher & $14(14.1 \%)$ & $11(16.4 \%)$ & $19(10.6 \%)$ & \\
\hline \multicolumn{5}{|l|}{ Epilepsy syndrome: } \\
\hline Focal epilepsy $(\mathrm{FE})^{\mathrm{a}}$ & - & - & $90(51.4 \%)$ & \\
\hline Generalized epilepsy $(\mathrm{GE})^{\mathrm{b}}$ & - & - & $85(48.6 \%)$ & \\
\hline
\end{tabular}

${ }^{\mathrm{a}}$ Note. Focal epilepsy syndromes: BECTS $(n=41)$, BOE $(n=2)$, TLE $(n=19)$, FLE $(n=9)$, FE Nos $(n=19)$.

${ }^{\mathrm{b}}$ Generalized epilepsy syndromes: Absence $(n=27)$, JME $(n=37)$, GE Nos $(n=20)$.

cognition, behavior and brain imaging (cortical, subcortical, and cerebellar volumes).

Of the 42 uncorrected correlations involving cognitive, behavioral and neuroimaging measures, the median correlation was 0.06 . Looking more specifically at the measures of cognition/behavior and imaging, the median correlations were 0.08 and 0.05 , respectively, all approaching 0 . Given the lack of association between cases and first degree cousin performances on measures of cognition, behavior, and neuroimaging, the results suggest at most a very weak genetic influence on control group performance, inferring that firstdegree cousins serve as unbiased controls for cognitive, behavioral, and neuroimaging research in pediatric epilepsy.

This study was reviewed and approved by the Institutional Review Board of each institution. On the day of study participation, families and children gave informed consent and assent, respectively, and all procedures were consistent with the Declaration of Helsinki (1991) (World Medical Association Declaration of Helsinki, 1991).

\section{Procedures}

For this investigation, parents of children with new-onset epilepsy and healthy controls completed structured interviews and questionnaires characterizing the participating child's gestation, delivery, neurodevelopment, and seizure history. To determine rates of academic services, parents were questioned through a structured interview about their child's school progress and, in particular, specific educational services provided to address academic problems. These services included the traditional individualized educational plan (IEP) or 504 plan, as well as early childhood interventions including speech therapy, physical therapy, occupational therapy, mandatory summer school, grade retention, special tutoring services (e.g., Title 1 reading), and other specific educational services. This interview was conducted blind to cognitive and behavioral results. Participating child and parent were interviewed separately and completed the Kiddie Schedule for Affective Disorders and Schizophrenia (K-SADS) (Kaufman, Birmaher, Brent, \& Rao, 1997). Sibling ADHD diagnosis was determined through the parent K-SADS interview for siblings of children with epilepsy who met the study criteria.

All parents completed the Child Behavior Checklist for children age 6-18 (CBCL/6-18) from the Achenbach System of Empirically Based Assessment (ASEBA) (Achenbach \& Rescorla, 2001) and the Behavior Rating Inventory of Executive Function (BRIEF) (Gioia, Isquith, Guy, \& Kenworthy, 2000). In addition, parents of children with epilepsy provided neurodevelopmental and academic history, and completed CBCL and BRIEF questionnaires for all applicable unaffected siblings. All pertinent medical records for children with epilepsy were obtained after signed release of information was obtained from the parent.

The dependent variables of interest were as follows: (i) Total Competence (higher scores indicating higher level of social competence) and Total Problems (higher scores indicating higher number of behavioral problems) summary scales from parent completed CBCL/6-18; (ii) Metacognition Index (MI) and Behavior Regulation Index (BRI) scales from 
parent completed BRIEF; (iii) history of education and academic services; and (iv) lifetime ADHD diagnosis as determined by K-SADS. CBCL and BRIEF variables were continuous, while ADHD diagnosis and academic services were dichotomous (yes/no). As a result of the group mean scores for CBCL and BRIEF scales mainly falling in a range that is not considered "clinically significant," we also conducted secondary analyses examining the proportion of clinically elevated scores for Total Competence, Total Problems, MI, and BRI scales.

The CBCL Total Competence scale consists of items assessing the child's involvement in activities (i.e., sports, hobbies, and house duties), their social interactions (i.e., involvement in extracurricular activities at school, interactions with friends, and social behaviors), and general academic performance. Higher Total Competence T-scores indicated higher level of function with scores of 35 and lower indicating a clinical level of impairment. The Total Problems scale is made up of two subscales: Internalizing and Externalizing Problems. Internalizing Problems consist of items assessing anxiousness, being withdrawn or depressed, and somatic complaints (i.e., nightmares, fatigue, stomach complains, and headaches). Externalizing Problems include items assessing rule breaking (i.e., swearing, stealing, and truancy from school) and aggressive behaviors (i.e., arguing, bullying, and threatening others). Higher Total Problems T-scores indicate higher level of impairment with scores of 65 and higher indicating clinical significance. Despite the disparate items, the T-scores for Internalizing and Externalizing subscales are highly correlated (current sample: $\mathrm{R}^{2}=0.67$; $p<.01$ ), and as a result we have chosen to examine Total Problems rather than the individual sub-scales.

The BRIEF BRI measures the child's ability to shift their cognitive focus and modulate their emotions/behaviors through appropriate inhibitory controls. The MI assesses the child's ability to initiate, plan, organize, and preserve futureoriented problem solving in working memory. Higher T-scores on BRI and MI indicate lower level of function and scores of 65 and higher are considered of potential clinical significance.

\section{Statistical Analyses}

To accommodate our study design with multiple children per family, linear mixed effect models with random intercepts (McCulloch, Searle, \& Neuhaus, 2008) were used for analysis of the four continuous variables using SAS 9.4 PROC MIXED, and logistic regression models with normally distributed random intercepts (McCulloch et al., 2008) were used for the two binary outcomes using STATA 15 xtlogit. Each model treated group (Epilepsy, Siblings, Controls) as a factor to test for among group differences in a global $2 \mathrm{df}$ test. Age and gender were adjusted as covariates. The analyses described above involved six tests; to control family-wise, or overall, Type I error rate, at alpha $=0.05$, we used the Bonferroni procedure to adjust for multiple comparisons, declaring group differences as significant when $p<.05 / 6$.
Post hoc pair-wise comparison tests were only performed when overall tests remained significant after the Bonferroni procedure. Model results are presented in terms of groupspecific proportions or means, using fitted models to adjust to the age-by-sex distribution of the overall sample, and averaging out random effects.

To examine whether there were significant group differences on rates of scores classified as clinically significant, CBCL Total Competence and Total Problems, and BRIEF Behavioral Regulation Index and Metacognition Index, T-scores were recoded as dichotomous variables (clinically significant: yes or no). Pearson's Chi Square was used to assess among group differences on the clinical significance of the T-scores.

\section{RESULTS}

There were significant differences (all $p \leq .003$ before Bonferroni adjustment) between the three groups on all six dependent variable endpoints (Table 2); as such, pairwise comparisons were conducted for each dependent variable.

\section{Lifetime ADHD Diagnosis and Academic Service Rates}

Age- and sex-adjusted lifetime ADHD diagnosis rates were significantly higher for children with epilepsy (29\%) compared with their unaffected siblings $(13 \% ; p<.02)$ and controls $(8 \% ; p<.001)$. The group difference in rates of ADHD between unaffected siblings and controls $(p=.38)$ was not significant, although estimates were somewhat different. Adjusted proportions and standard errors are listed in Table 2.

Academic service rates were significantly higher for children with epilepsy $(51 \%)$ compared with their healthy siblings $(31 \% ; p=.01)$ and controls $(18 \% ; p<.001)$. The difference in rate of academic service use between healthy siblings and controls ( $p=.07$ ) was suggestive of a difference, but not significant. Adjusted proportions and standard errors are listed in Table 2. A summary of the rates of specific type of academic services received by group are listed in Table 3 .

\section{CBCL Total Competence and Total Problems}

Age- and sex-adjusted Total Competence was significantly higher for controls $(\mathrm{M}=52.3)$ compared with both children with epilepsy $(\mathrm{M}=44.6 ; p<.001)$ and their unaffected siblings $(M=45.9 ; p<.001)$. The difference between children with epilepsy and their unaffected siblings was small and not significant $(p=.22)$. While differences among groups were detected on mean scale scores, the means were generally in the average range. As such, rates of clinically significant T-scores for Total Competence were also examined and found to be significantly different between the groups $\left(\chi^{2}(2, N=342)=13.45 ; p<.001\right)$. Only $14 \%$ of healthy controls had clinically significant T-scores compared to $28 \%$ of siblings and $35 \%$ of probands with epilepsy. 
Table 2. Marginal proportions (P), marginal means (T-score), and standard errors (SE) by group

\begin{tabular}{lccccc}
\hline \hline & \multicolumn{5}{c}{ Group } \\
\cline { 2 - 5 } & $\begin{array}{c}\text { Controls (a) } \\
(N=99)\end{array}$ & $\begin{array}{c}\text { Siblings }(\mathrm{b}) \\
(N=67)\end{array}$ & $\begin{array}{c}\text { Epilepsy (c) } \\
(N=180)\end{array}$ & \\
\hline Categorical measures & $\mathrm{P}(S E)$ & $\mathrm{P}(S E)$ & $\mathrm{P}(S E)$ & $\chi^{2 * *}$ & $p$-Value** \\
\hline Education services & $0.18(0.04)^{\mathrm{c}}$ & $0.31(0.06)^{\mathrm{c}}$ & $0.51(0.04)^{\mathrm{a}, \mathrm{b}}$ & 20.03 & .0005 \\
Lifetime diagnosis of ADHD & $0.08(0.03)^{\mathrm{c}}$ & $0.13(0.05)^{\mathrm{c}}$ & $0.29(0.03)^{\mathrm{a}, \mathrm{b}}$ & 16.09 & .0029 \\
\hline Continuous measures & $\mathrm{M}(S E)$ & $\mathrm{M}(S E)$ & $\mathrm{M}(S E)$ & $F(2,49)^{*}$ & $p$-Value \\
\hline CBCL & & & & 13.23 & $<.0001$ \\
Total Competence & $52.3(1.3)^{\mathrm{b}, \mathrm{c}}$ & $45.7(1.2)^{\mathrm{a}}$ & $44.6(0.8)^{\mathrm{a}}$ & 25.68 & $<.0001$ \\
Total Problems & $45.8(1.4)^{\mathrm{b}, \mathrm{c}}$ & $50.5(1.4)^{\mathrm{a}, \mathrm{c}}$ & $56.2(0.8)^{\mathrm{a}, \mathrm{b}}$ & & $<.0001$ \\
BRIEF & & & & \\
Metacognition Index & $48.0(1.4)^{\mathrm{c}}$ & $50.3(1.4)^{\mathrm{c}}$ & $56.4(0.8)^{\mathrm{a}, \mathrm{b}}$ & 19.81 & $<.0001$ \\
Behavioral Regulation Index & $46.5(1.3)^{\mathrm{c}}$ & $48.2(1.3)^{\mathrm{c}}$ & $53.5(0.8)^{\mathrm{a}, \mathrm{b}}$ & 15.38 & \\
\hline \hline
\end{tabular}

Note. ${ }^{\mathrm{a}, \mathrm{b}, \mathrm{c}}$ Denotes significant difference among groups $(p<.05)$ : $\mathrm{a}=$ controls, $\mathrm{b}=$ siblings, $\mathrm{c}=$ children with epilepsy.

*Estimates are adjusted to the age $\mathrm{x}$ sex distribution across the entire sample after linear or logistic random effects model fitting.

**Chi-square or $F$ statistic, along with $p$-value, for testing any difference among the three groups, before Bonferroni correction; test results from logistic $(\mathrm{P})$ or linear $(\mathrm{M})$ random effects model fits.

Age- and sex-adjusted Total problems were significantly lower for controls $(\mathrm{M}=45.8)$ compared with both children with epilepsy $(\mathrm{M}=56.2 ; p<.001)$ and their unaffected siblings $(\mathrm{M}=50.5 ; p<0.05)$. Children with epilepsy also had significantly higher Total Problems scores than their unaffected siblings $(p<0.001)$. Mean scores for Total Competence and Total Problems are summarized in Figure 1. Again, because these means were generally in the average range, rates of clinically significant T-scores for Total Problems were also examined and found to be significantly different among the groups $\left(\chi^{2}(2, N=343)=22.31 ; p<.001\right)$. Only $7 \%$ of healthy controls and $3 \%$ of unaffected siblings had clinically significant $\mathrm{T}$-scores compared to $24 \%$ of probands with epilepsy.

\section{BRIEF Behavior Regulation Index and Metacognition Index}

The BRI score was significantly higher for children with epilepsy (age- and sex-adjusted $\mathrm{M}=53.5$ ) compared with their unaffected siblings $(\mathrm{M}=48.0 ; p<.001)$ and controls

Table 3. Lifetime academic services rates by group

\begin{tabular}{lccc}
\hline \hline & $\begin{array}{c}\text { Controls } \\
(N=99)\end{array}$ & $\begin{array}{c}\text { Siblings } \\
(N=67)\end{array}$ & $\begin{array}{c}\text { Epilepsy } \\
(N=180)\end{array}$ \\
\hline $\begin{array}{l}\text { Lifetime academic service } \\
\text { rates }\end{array}$ & $18(18.2 \%)$ & $21(31.3 \%)$ & $92(51.1 \%)$ \\
$\begin{array}{l}\text { Individualized education } \\
\text { plan (IEP) }\end{array}$ & $2(2.0 \%)$ & $9(13.4 \%)$ & $49(27.2 \%)$ \\
$\quad$ Birth-Age 3 & $1(1.0 \%)$ & $7(10.5 \%)$ & $15(8.3 \%)$ \\
$\begin{array}{l}\text { Early Childhood } \\
\text { School Services }\end{array}$ & $5(5.1 \%)$ & $3(4.5 \%)$ & $21(11.7 \%)$ \\
\hline \hline
\end{tabular}

$(\mathrm{M}=46.5 ; p<.001)$. No significant differences were found between unaffected siblings and controls $(p=.35)$. Rates of clinically significant $\mathrm{T}$-scores for the Behavior Regulation Index were significantly different among the groups $\left(\chi^{2}(2\right.$, $N=346)=17.94 ; p<.001)$. Only $5.1 \%$ of healthy controls and $4.5 \%$ of unaffected siblings had clinically significant T-scores compared to $20 \%$ of probands with epilepsy.

The Metacognition Index was significantly higher for children with epilepsy (age-and-sex adjusted $\mathrm{M}=56.4$ ) compared with their unaffected siblings $(\mathrm{M}=50.3 ; p<.001)$ and controls $(\mathrm{M}=48.0 ; p<.001)$. No significant differences were found between their unaffected siblings and controls $(p=.19)$. Rates of clinically significant T-scores for the Metacognition Index were significantly different among the groups $\left(\chi^{2}(2, N=346)=27.60 ; p<.001\right)$. Only $5.1 \%$ of healthy controls and $7.5 \%$ of unaffected siblings had clinically significant $\mathrm{T}$-scores compared to $27.2 \%$ of probands with epilepsy.

Overall, there appeared to be an effect of epilepsy, unassociated with family relatedness, in regard to rates of ADHD as well as executive dysfunction including behavioral regulation and metacognition, reflected by significantly higher rates of abnormality in the children with epilepsy compared with both unaffected siblings and controls, with much weaker differences between the latter two groups (Figure 1).

\section{DISCUSSION}

To determine the relative contributions of epilepsy and familial aggregation to neurobehavioral comorbidities commonly associated with childhood epilepsies, we compared children with epilepsy, their unaffected siblings, and typically developing controls across a broad range of comorbidities including ADHD, academic problems, parent-reported 


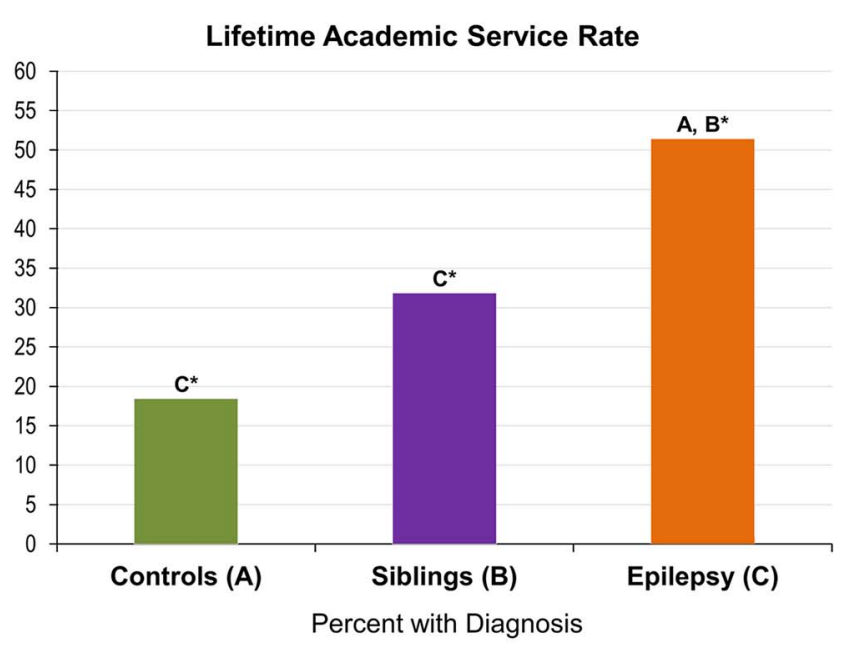

Total Competence

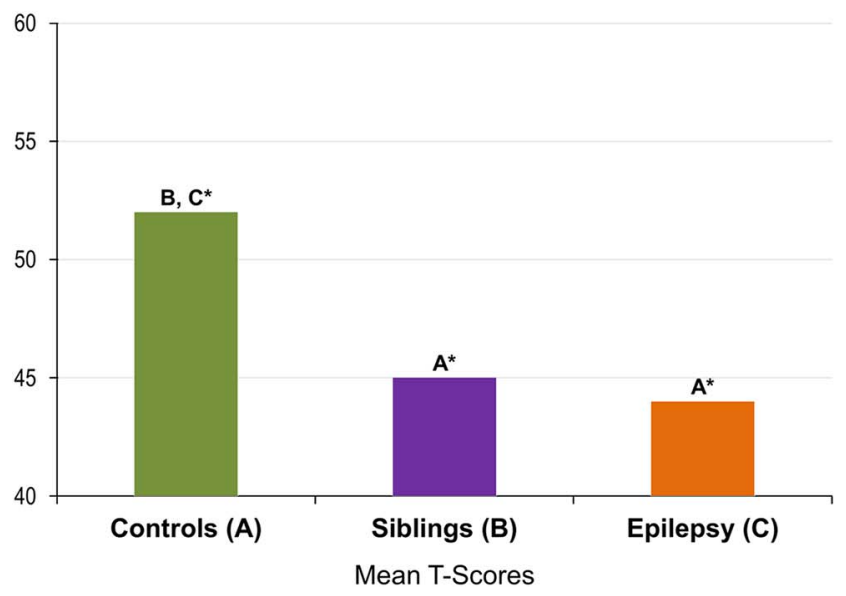

Attention Deficit Disorders (ADHD)

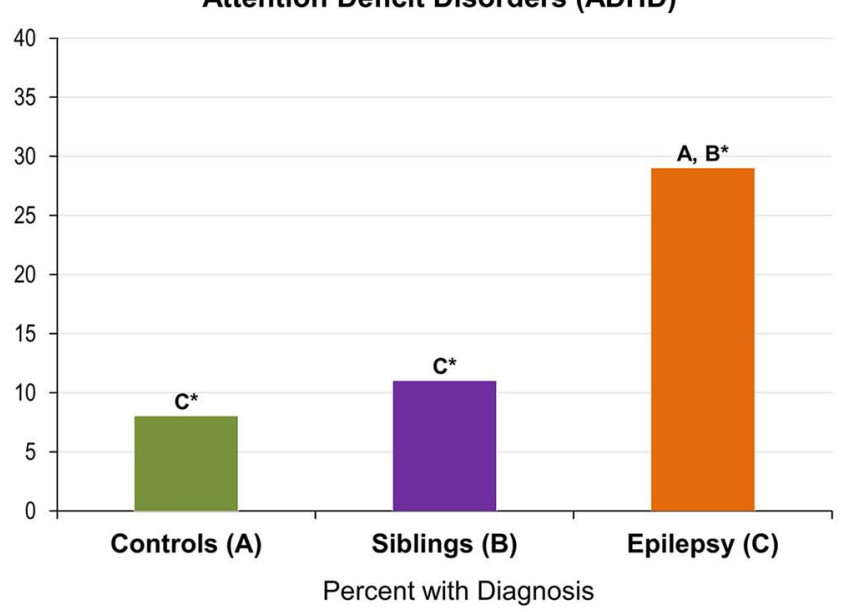

Total Problems

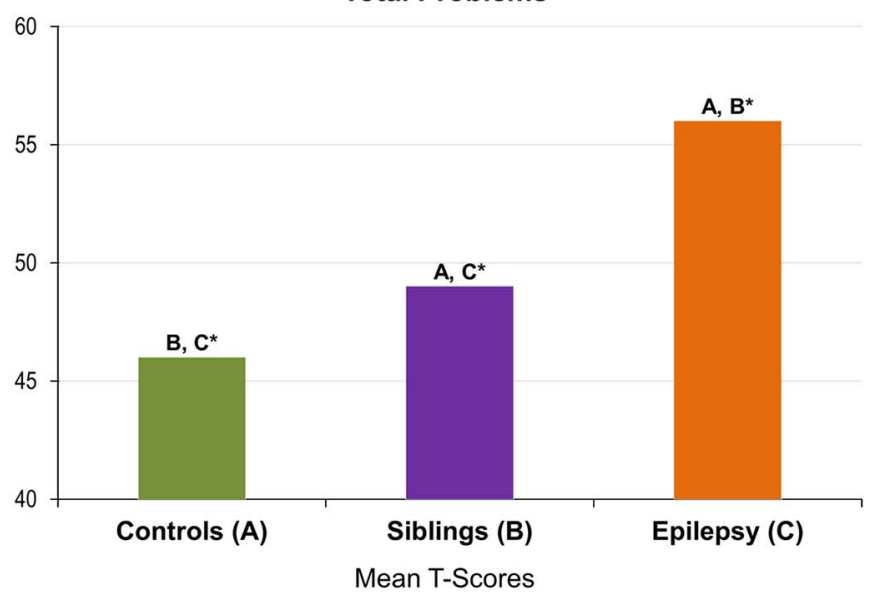

Fig. 1. Rates of comorbidity in children with epilepsy, their siblings, and controls. *A, B, C denotes significant differences among groups: $\mathrm{A}=$ controls, $\mathrm{B}=$ siblings, $\mathrm{C}=$ epilepsy.

social competence and behavioral problems as well as assessments of day-to-day executive function. To our knowledge, this is the broadest examination to date of the relationship between family relatedness and diverse behavioral and academic complications commonly reported among children with epilepsy.

We hypothesized that the siblings of children with epilepsy will have lower rates of comorbidities and behavior problems compared to children with epilepsy, but higher rates than the healthy controls. Of interest, varying patterns of association with the comorbidity measures were demonstrated. Specifically, there appeared to be an effect of epilepsy, unassociated with family relatedness, in regard to rates of ADHD as well as executive dysfunction including behavioral regulation and metacognition, reflected by significantly higher rates of abnormality in the children with epilepsy compared with both unaffected siblings and controls, with much weaker differences between the latter two groups (Figure 1). These differences were reflected both in terms of mean score differences as well as rates exceeding critical cut points. Our findings of elevated rates of ADHD and executive dysfunction in children with epilepsy compared to controls are consistent with previous literature (Berl et al., 2015; MacAllister et al., 2012; Sherman et al., 2007), the current results obtained in children with new onset epilepsies and also suggesting the contribution of family relatedness.

There appeared to be a broader contribution of family relatedness to measures of social competence and behavioral problems. Consistent with the literature that has compared children with epilepsy to either siblings or healthy controls, lower competence and higher total behavioral problems were evident in the children with epilepsy compared with both unaffected siblings and typically developing controls (Aronu \& Iloeje, 2011; Austin et al., 2001). However, unaffected siblings exhibited significantly lower competence and higher behavioral problems compared to the controls, consistent with more recent findings suggesting a contribution of family relatedness, reflecting an impact of genetic, social, or other factors (Hesdorffer et al., 2012).

Specifically, the presence of an effect of family relatedness or family aggregation leads to the question of the etiology of the effect. Quite often the presence of an effect of family aggregation leads to speculation regarding possible genetic influences even though no genetic material has been collected or analyzed. 
A competing hypothesis is that family aggregation may be related to "environmental" factors such as family cohesion, parenting styles, social disadvantage, or other factors. An important direction for the future is to parse out the contribution of these competing etiologies for those dependent measures shown to reliably result in "familial aggregation".

Finally, regarding academic problems, children with epilepsy again had higher rates of supportive academic services than unaffected siblings and controls, and a trend was observed of more problems in the unaffected siblings compared with controls $(51 \%$ vs. $31 \%$ vs. $18 \%)$. While previous studies support findings of elevated academic service rates in children with epilepsy (Almane et al., 2015; Berg et al., 2005; Overvliet et al., 2011; Sogawa, Masur, O'Dell, Moshe, \& Shinnar, 2010), the noted elevated rates of academic services in epilepsy siblings is a unique finding of the current study. Academic service rates by group are summarized in Figure 1. Sample rates by the specific type of academic services received are listed in Table 3.

In the broader child epilepsy literature, a question has been raised regarding the degree to which proxy-based reports (e.g., from parents) accurately reflect the emotional-behavioral status of their children with epilepsy (Eom, Caplan, \& Berg, 2016), specifically suggesting that parent-proxy behavior measures such as the CBCL are contaminated by the emotional impact of epilepsy on the parents themselves. In contrast to this perspective, we have found parent reports of competence, behavioral problems, academic difficulties and ADHD as assessed here to have direct neuroanatomic correlates in the children (Dabbs, Jones, Jackson, Seidenberg, \& Hermann, 2013; Hermann et al., 2006; Saute et al., 2014).

Specifically, parent reports of higher (better) social competence skills are associated with increased cortical thickness, especially in frontal regions. Parent reports of behavioral problems are associated with patterns of decreased cortical thickness that vary as a function of the specific behavioral issue under investigation. Thus, the parent-report version of the CBCL is associated with variations in cortical thickness among children with epilepsy with anatomic abnormalities specific to selected competence and behavioral problem scales, with more reliable and robust patterns of thinning across scales assessing externalizing behaviors, with generally less prominent findings on scales assessing internalizing behaviors. Parents' observations and reports of competence and behavior problems in their children have direct neurobiological correlates in the brains of their children and hence are an important area of inquiry.

The ecological implications of these findings reported here suggest that in clinical work there is significant utility to obtaining a broad familial history which will serve as an important component of understanding the neurobehavioral comorbidities of a child with epilepsy. We focused here on the status of siblings, but broader familial investigation (e.g., parents) is likely pertinent not only to behavioral issues and quality of life (Mendes, Crespo, \& Austin, 2017), but to cognition and academic performance as well (Fastenau et al., 2004) as is increasingly appreciated.

\section{LIMITATIONS AND FUTURE DIRECTIONS}

Several limitations and opportunities for future research are associated with this investigation. First, due to limited sample size we were not able to examine whether comorbidity rates or behavior problems differed for siblings of children with focal vs. generalized epilepsy. One might hypothesize that children with the "genetic" generalized epilepsies may be more likely to have siblings with targeted comorbidities than children with focal epilepsies, but this remains to be determined. Second, again due to limited sample size, we were not able to examine group differences for the specific type of academic services (IEP, Birth-Age 3, Early Childhood, and School Services). Third, many of the contrasts of group means, while revealing significant differences among groups, remained in the generally average or normal range. Thus, examination of critical clinically meaningful cut points is essential to gauge the clinical significance of the findings, as was done here as well. Fourth, the presence of an effect of family relatedness or family aggregation leads to the question of the etiology of that effect, something which we cannot untangle here but which is important for future research. Quite often the presence of an effect of family aggregation leads to speculation regarding possible genetic influences even though no genetic material has been collected or analyzed.

A competing hypothesis is that family aggregation may be related to "environmental" factors such as family cohesion, parenting styles, social disadvantage, or any number of other factors. An important direction for the future is to parse out the contribution of these competing etiologies for those dependent measures shown to reliably result in "familial aggregation". Fifth, our sample consists of children with uncomplicated idiopathic epilepsies. How these findings would translate to a cohort of children with more complicated and treatment resistant epilepsies remains to be determined. Sixth, the siblings did not undergo formal neuropsychological assessment and direct comparison of cognitive status would be very valuable going forward. Finally, the sample size in the control and sibling groups was more limited, so while we were able to reliably detect differences between the epilepsy group and either of the other two groups, there were suggestions of differences between control and sibling groups that did not reach statistical significance.

In conclusion, examining a broad range of potential comorbidities of childhood epilepsy, there appears to be variable influence of epilepsy compared to familial relatedness across the problems of interest. There appears to be no simple and generalizable relationship between the neurobehavioral comorbidities of childhood epilepsy and the risk conferred by the presence of epilepsy in comparison to family relatedness. Some comorbidities are clearly associated with the presence of epilepsy independent of family relatedness, other comorbidities show a contribution of family relatedness, and there was no area of comorbidity where there were no differences among groups.

The mechanism(s) underlying elevated comorbidities in unaffected siblings remains to be determined and may reflect 
a genetic contribution, the effects of family environment, or other factors. Untangling the path by which family relatedness influences comorbidity risk is an important task for the future (Badawy et al., 2013; Clarke et al., 2007; Levav et al., 2002; Smith et al., 2012). The degree of risk associated with epilepsy relative to family relatedness appears to vary across specific individual comorbidities.

\section{ACKNOWLEDGMENTS}

Disclosure of Conflicts of Interest: None of the authors have any conflict of interest to disclose. Financial Support: This work was supported by NIH 3RO1-44351 and the Clinical and Translational Science Award (CTSA) program, previously through the National Center for Research Resources (NCRR) grant 1UL1RR025011, and now by the National Center for Advancing Translational Sciences (NCATS), grant 9U54TR000021. The funding sources had no role in study design; in collection, analysis and interpretation of data; in the writing of the report; or in the decision to submit the article for publication. We thank Raj Sheth, MD, and Lucyna Zawadzki, MD, for their contributions to the study. Also greatly appreciated are Melissa Hanson and Kate Young for overall study coordination, participant recruitment, cognitive assessment, and data management.

\section{REFERENCES}

Achenbach, T.M., \& Rescorla, L.A. (2001). Manual for the ASEBA School-Age forms and profiles. Burlington, VT: University of Vermont, Research Center for Children, Youth and Families.

Alhusaini, S., Scanlon, C., Ronan, L., Maguire, S., Meaney, J.F., Fagan, A.J., ... Cavalleri, G.L. (2013). Heritability of subcortical volumetric traits in mesial temporal lobe epilepsy. PLoS One, 8 (4), e61880. doi:10.1371/journal.pone.0061880

Almane, D., Jones, J.E., Jackson, D.C., Seidenberg, M., Koehn, M., Hsu, D.A., \& Hermann, B.P. (2015). Brief clinical screening for academic underachievement in new-onset childhood epilepsy: Utility and longitudinal results. Epilepsy \& Behavior, 43, 117-121. doi:10.1016/j.yebeh.2014.12.002

Aronu, A.E., \& Iloeje, S.O. (2011). Behavioral problems of siblings of epileptic children in Enugu. Nigerian Journal of Clinical Practice, 14(2), 132-136. doi:10.4103/1119-3077.84000

Austin, J.K., Harezlak, J., Dunn, D.W., Huster, G.A., Rose, D.F., \& Ambrosius, W.T. (2001). Behavior problems in children before first recognized seizures. Pediatrics, 107(1), 115-122.

Austin, J.K., Huberty, T.J., Huster, G.A., \& Dunn, D.W. (1998). Academic achievement in children with epilepsy or asthma. Developmental Medicine \& Child Neurology, 40(4), 248-255.

Badawy, R.A., Vogrin, S.J., Lai, A., \& Cook, M.J. (2013). Capturing the epileptic trait: Cortical excitability measures in patients and their unaffected siblings. Brain, 136(Pt 4), 1177-1191. doi:10.1093/brain/ awt047

Berg, A.T., Smith, S.N., Frobish, D., Levy, S.R., Testa, F.M., Beckerman, B., \& Shinnar, S. (2005). Special education needs of children with newly diagnosed epilepsy. Developmental Medicine \& Child Neurology, 47(11), 749-753.

Berg, A.T., Vickrey, B.G., Testa, F.M., Levy, S.R., Shinnar, S., \& DiMario, F. (2007). Behavior and social competency in idiopathic and cryptogenic childhood epilepsy. Developmental Medicine \& Child Neurology, 49(7), 487-492.

Berl, M.M., Terwilliger, V., Scheller, A., Sepeta, L., Walkowiak, J., \& Gaillard, W.D. (2015). Speed and complexity characterize attention problems in children with localization-related epilepsy. Epilepsia, 56(6), 833-840. doi:10.1111/epi.12985

Chowdhury, F.A., Elwes, R.D., Koutroumanidis, M., Morris, R.G., Nashef, L., \& Richardson, M.P. (2014). Impaired cognitive function in idiopathic generalized epilepsy and unaffected family members: An epilepsy endophenotype. Epilepsia, 55(6), 835-840. doi:10.1111/epi.12604

Clarke, T., Strug, L.J., Murphy, P.L., Bali, B., Carvalho, J., Foster, S., ... Pal, D.K. (2007). High risk of reading disability and speech sound disorder in rolandic epilepsy families: Casecontrol study. Epilepsia, 48(12), 2258-2265.

Dabbs, K., Jones, J.E., Jackson, D.C., Seidenberg, M., \& Hermann, B.P. (2013). Patterns of cortical thickness and the Child Behavior Checklist in childhood epilepsy. Epilepsy \& Behavior, 29(1), 198-204. doi:10.1016/j.yebeh.2013.07.008

Davies, S., Heyman, I., \& Goodman, R. (2003). A population survey of mental health problems in children with epilepsy. Developmental Medicine \& Child Neurology, 45(5), 292-295.

Eom, S., Caplan, R., \& Berg, A.T. (2016). Behavioral problems and childhood epilepsy: Parent vs child perspectives. Journal of Pediatrics, 179, 233-239, e235. doi:10.1016/j.jpeds.2016.08.096

Fastenau, P.S., Johnson, C.S., Perkins, S.M., Byars, A.W., deGrauw, T.J., Austin, J.K., \& Dunn, D.W. (2009). Neuropsychological status at seizure onset in children: Risk factors for early cognitive deficits. Neurology, 73(7), 526-534. doi:10.1212/ WNL.0b013e3181b23551 [pii].

Fastenau, P.S., Shen, J., Dunn, D.W., Perkins, S.M., Hermann, B.P., \& Austin, J.K. (2004). Neuropsychological predictors of academic underachievement in pediatric epilepsy: Moderating roles of demographic, seizure, and psychosocial variables. Epilepsia, 45(10), 1261-1272. doi:10.1111/j.0013-9580.2004.15204.x

Gioia, G.A., Isquith, P.K., Guy, S.C., \& Kenworthy, L. (2000). Behavior rating inventory of executive function. Child Neuropsychology, 6(3), 235-238. doi:10.1076/chin.6.3.235.3152

Hanson, M., Morrison, B., Jones, J.E., Jackson, D.C., Almane, D., Seidenberg, M., ... Hermann, B.P. (2017). Control groups in paediatric epilepsy research: Do first-degree cousins show familial effects? Epileptic Disorders, 19(1), 49-58. doi:10.1684/ epd.2017.0898

Hermann, B., Jones, J., Sheth, R., Dow, C., Koehn, M., \& Seidenberg, M. (2006). Children with new-onset epilepsy: Neuropsychological status and brain structure. Brain, 129(Pt 10), 2609-2619.

Hesdorffer, D.C., Caplan, R., \& Berg, A.T. (2012). Familial clustering of epilepsy and behavioral disorders: Evidence for a shared genetic basis. Epilepsia, 53(2), 301-307. doi:10.1111/ j.1528-1167.2011.03351.x

Hesdorffer, D.C., Ludvigsson, P., Olafsson, E., Gudmundsson, G., Kjartansson, O., \& Hauser, W.A. (2004). ADHD as a risk factor for incident unprovoked seizures and epilepsy in children. Archives of General Psychiatry, 61(7), 731-736. doi:10.1001/ archpsyc.61.7.731

Hoare, P. (1984). The development of psychiatric disorder among schoolchildren with epilepsy. Developmental Medicine \& Child Neurology, 26(1), 3-13.

Hoie, B., Mykletun, A., Sommerfelt, K., Bjornaes, H., Skeidsvoll, H., \& Waaler, P.E. (2005). Seizure-related factors and non-verbal intelligence in children with epilepsy. A population-based study from Western Norway. Seizure, 14(4), 223-231.

Iqbal, N., Caswell, H., Muir, R., Cadden, A., Ferguson, S., Mackenzie, H., ... Duncan, S. (2015). Neuropsychological profiles of patients with juvenile myoclonic epilepsy and their 
siblings: An extended study. Epilepsia, 56(8), 1301-1308. doi:10.1111/epi.13061

Jones, J.E., Austin, J.K., Caplan, R., Dunn, D., Plioplys, S., \& Salpekar, J.A. (2008). Psychiatric disorders in children and adolescents who have epilepsy. Pediatrics in Review, 29(2), e9-e14. doi:10.1542/pir.29-2-e9

Jones, J.E., Watson, R., Sheth, R., Caplan, R., Koehn, M., Seidenberg, M., \& Hermann, B. (2007). Psychiatric comorbidity in children with new onset epilepsy. Developmental Medicine \& Child Neurology, 49(7), 493-497. doi:10.1111/j.1469-8749. 2007.00493.x

Kaufman, J., Birmaher, B., Brent, D., \& Rao, U. (1997). Schedule for affective disorders and schizophrenia for school-age childrenpresent and lifetime version (K-SADS-PL): Initial reliability and validity data. Journal of the American Academy of Child \& Adolescent Psychiatry, 36(7), 980-988.

Levav, M., Mirsky, A.F., Herault, J., Xiong, L., Amir, N., \& Andermann, E. (2002). Familial association of neuropsychological traits in patients with generalized and partial seizure disorders. Journal of Clinical and Experimental Neuropsychology, 24(3), 311-326. doi:10.1076/jcen.24.3.311.985

Lin, J.J., Mula, M., \& Hermann, B.P. (2012). Uncovering the neurobehavioural comorbidities of epilepsy over the lifespan. Lancet, 380(9848), 1180-1192. doi:10.1016/S0140-6736(12) 61455-X

MacAllister, W.S., \& Schaffer, S.G. (2007). Neuropsychological deficits in childhood epilepsy syndromes. Neuropsychology in Review, 17(4), 427-444.

MacAllister, W.S., Vasserman, M., Vekaria, P., Miles-Mason, E., Hochsztein, N., \& Bender, H.A. (2012). Neuropsychological endophenotypes in ADHD with and without epilepsy. Applied Neuropsychology. Child, 1(2), 121-128. doi:10.1080/ 21622965.2012.709421

McCulloch, C.E., Searle, S.R., \& Neuhaus, J.M. (2008). Generalized, linear, and mixed models (2nd Ed.). New York: Wiley.

McDermott, S., Mani, S., \& Krishnawami, S. (1995). A populationbased analysis of specific behavior problems associated with childhood seizures. Journal of Epilepsy, 8(2), 110-118. doi:http://dx.doi.org/10.1016/0896-6974(95)00019-A

McNelis, A.M., Johnson, C.S., Huberty, T.J., \& Austin, J.K. (2005). Factors associated with academic achievement in children with recent-onset seizures. Seizure, 14(5), 331-339.

Mendes, T.P., Crespo, C.A., \& Austin, J.K. (2017). Family cohesion, stigma, and quality of life in dyads of children with epilepsy and their parents. Journal of Pediatric Psychology, 42(6), 689-699. doi:10.1093/jpepsy/jsw105

Oostrom, K.J., Smeets-Schouten, A., Kruitwagen, C.L., Peters, A.C., Jennekens-Schinkel, A., \& Dutch Study Group of Epilepsy in Childhood. (2003). Not only a matter of epilepsy: Early problems of cognition and behavior in children with "epilepsy only"A prospective, longitudinal, controlled study starting at diagnosis. Pediatrics, 112(6 Pt 1), 1338-1344.

Overvliet, G.M., Aldenkamp, A.P., Klinkenberg, S., Vles, J.S., \& Hendriksen, J. (2011). Impaired language performance as a precursor or consequence of Rolandic epilepsy? Journal of the Neurological Sciences, 304(1-2), 71-74. doi:10.1016/j. jns.2011.02.009

Parrish, J., Geary, E., Jones, J., Seth, R., Hermann, B., \& Seidenberg, M. (2007). Executive functioning in childhood epilepsy: Parent-report and cognitive assessment. Developmental Medicine \& Child Neurology, 49(6), 412-416.

Pohlmann-Eden, B., Aldenkamp, A., Baker, G.A., Brandt, C., Cendes, F., Coras, R., ... Hermann, B.P. (2015). The relevance of neuropsychiatric symptoms and cognitive problems in new-onset epilepsy - Current knowledge and understanding. Epilepsy \& Behavior, 51, 199-209. doi:10.1016/j.yebeh.2015.07.005

Rantanen, K., Eriksson, K., \& Nieminen, P. (2012). Social competence in children with epilepsy-A review. Epilepsy \& Behavior, 24(3), 295-303. doi:10.1016/j.yebeh.2012.04.117

Russ, S.A., Larson, K., \& Halfon, N. (2012). A national profile of childhood epilepsy and seizure disorder. Pediatrics, 129(2), 256-264. doi:10.1542/peds.2010-1371

Rutter, M., Graham, P., \& Yule, W. (1970). A neuropsychiatric study in children. Clinics in Developmental Medicine (Vol. Nos. 35/36) London: SIMP with Heinemann.

Saute, R., Dabbs, K., Jones, J.E., Jackson, D.C., Seidenberg, M., \& Hermann, B.P. (2014). Brain morphology in children with epilepsy and ADHD. PLoS One, 9(4), e95269. doi:10.1371/ journal.pone.0095269

Sherman, E.M., Slick, D.J., Connolly, M.B., \& Eyrl, K.L. (2007). ADHD, neurological correlates and health-related quality of life in severe pediatric epilepsy. Epilepsia, 48(6), 1083-1091. doi:10.1111/j.1528-1167.2007.01028.x

Smith, A.B., Kavros, P.M., Clarke, T., Dorta, N.J., Tremont, G., \& Pal, D.K. (2012). A neurocognitive endophenotype associated with rolandic epilepsy. Epilepsia, 53(4), 705-711. doi:10.1111/ j.1528-1167.2011.03371.x

Sogawa, Y., Masur, D., O’Dell, C., Moshe, S.L., \& Shinnar, S. (2010). Cognitive outcomes in children who present with a first unprovoked seizure. Epilepsia, 51, 2432-2439. doi:10.1111/ j.1528-1167.2010.02724.x

Wandschneider, B., Centeno, M., Vollmar, C., Symms, M., Thompson, P.J., Duncan, J.S., \& Koepp, M.J. (2014). Motor coactivation in siblings of patients with juvenile myoclonic epilepsy: An imaging endophenotype? Brain, 137(Pt 9), 2469-2479. doi:10.1093/brain/awu175

World Medical Association Declaration of Helsinki. (1991). The Journal of Law, Medicine \& Ethics, 19(3-4), 264-265. 